\title{
The Latest Developments of Guardianship Legal Issue in China
}

\author{
XIAO Yongping \\ Changjiang Distinguished Professor \\ Director of International Law Institute \\ Wuhan University \\ QIN Hongman \\ Dr. Assistant Professor \\ Zhejiang Sci-Tech University \\ Postdoctoral \\ Fudan University
}

\begin{abstract}
The latest developments of China's guardianship legal issues shall include two important laws--the GPCL and the Conflicts Act. The GPCL emphasizes the principle of being in favor of the interests of wards, respects the right of selfdetermination of the wards, adds 3 forms of guardianship, clarifies the duties of guardian. Article 30 of the Conflicts Act has four obvious deficiencies, even though it stipulates the application of guardianship and emphasizes the protection of the interests of the ward. Foreign-related guardianship cases in Chinese courts frequently present four characteristics: foreign element is subject, guardianship is about minors, using common procedures, and prefer using Chinese law. These characteristics also reflect the three shortcomings of the application of law. On the basis of the above analysis, we put forward four improvement suggestions from the substantive law perspective, and introduce five application methods from the conflict law perspective.
\end{abstract}

Keywords: New Rules in the GPCL, Guardianship Conflict Rules, the Scope of Guardianship, Principle of Protecting Interests of Wards, Party Autonomy in Eldly Guardianship

\section{The Two Important Acts}

Under Chinese legal system, the General Provisions of the Civil Law of the PRC of 2017 (the GPCL) ${ }^{1}$ and the Law of the PRC on the Laws Applicable to Foreign-related Civil Relations (the Conflicts Act) ${ }^{2}$ are the two important Acts regarding the guardianship legislation in China from substantive law and Conflicts law respectively.

\subsection{The New Developments of the GPCL}

The Chapter Two of the GPCL provides 14 Articles $^{3}$ regulating guardianship, in contrast, the General Principles of Civil Law of $1986^{4}$ had only 4 Articles. ${ }^{5}$ So guardianship system under the GPCL has been much improved in the following aspects:

First, the GPCL emphasizes the principle of being in favor of the interests of wards. Under Article 31 (2), where the court, the residents' committee, the villagers' committee or the civil affairs department designates the guardian, the principle of being in favor of the interests of wards shall be followed. Article 35 (1) also emphasizes this principle when it provides the responsibility of the guardian. In addition to the interests of the guardian, the guardian shall not dispose the property under guardianship. Under Article 36, the court shall disqualify the guardian, arrange necessary provisional guardianship measures, and designate another guardian in accordance with the law under the principle of most benefiting the ward.

\footnotetext{
${ }^{1}$ The GPCL was adopted by the 5th Session of the 12th National People's Congress of the PRC on March 15, 2017 and came into force on October 1, 2017.

${ }^{2}$ The Conflicts Act was adopted by the 17th Meeting of the Standing Committee of the 11th National People's Congress of the PRC on October 28, 2010 and came into force on April 1, 2011.

${ }^{3}$ Articles 26 to 39 of the GPCL.

${ }^{4}$ The Law was adopted by the fourth session of the 6th National People's Congress of PRC on April 12, 1986 and came into force on January 1, 1987.

${ }^{5}$ Articles 16 to 19 of the General Principles of Civil Law. 
Second, the GPCL respects the right of self-determination of the ward. Under Article 30, the true will of the ward shall be respected in the determination of guardian by agreement. Article 35 (2) and (3) also provides that in carrying out guardianship duties for minors and adults, the guardian must respect the age and mental status of the ward and respect his thoughts. Especially in the adult guardianship, the guardian should protect the adult's independent civil legal act conform to his intelligence and mental health, and shall not interfere in his treatment he has the ability to handle affairs.

Third, the GPCL adds 3 forms of guardianship. They are the appointed guardianship by article $29,{ }^{6}$ the temporary guardianship by Articles 31 (3) and 36 (1), ${ }^{7}$ the intended guardianship by Article $33 .{ }^{8}$

Fourth, the GPCL clarifies the duties of guardian. Article 34 of the GPCL clearly guarantees the guardian's duties in 3 sections. The first section classifies the duties of personal care, property care and legal representation. In addition to the provisions of the guardian's legal liability for failure to fulfill the duty and infringement of the lawful rights and interests of the ward, this article also stresses the protection of guardian's right to perform guardianship. By this way, Chinese law considers the guardianship as neither a simple right nor an absolute obligation, but a combination of rights and obligations.

Finally, the GPCL increases the situation of guardianship change including the guardian revocation and the guardianship termination by Article 36 and Article 39. ${ }^{9}$

\subsection{The Provision of the Conflicts Act}

Under Article 30 the Conflicts Act, guardianship is governed by the law of either party's habitual residence or nationality, depending on which law is more favorable to the protection of the rights of the ward. This Article demonstrates the principle of protecting the interests of the weak in private international law, embodies the legislative philosophy of human-oriented and conforms to the pursuit of substantive justice in contemporary private international law. ${ }^{10}$ In the guardianship relationship, the ward is often in a relatively weak position because of age, physiology and mental, so it can be tilted to protect the interests of the parties to some extent.

However, this Article has deficiencies as follows:

First, the scope of guardianship needs to be clarified. It is not clear that Article 30 only applies to personal care or both for personal care and the property guardianship; whether including both minor guardianship and adult guardianship or not. If adult guardianship is adopted, whether the new type of guardianship, such as the guardianship of the elderly, included or not. When the Conflicts Act passed, the Chinese guardianship system was far from perfect, such as the adults guardianship only covers the guardianship of mental patients. Since then, the content of adult guardianship has been supplemented in the GPCL. Therefore, the Conflicts Act may need to be further adjusted and crystallized whether it includes adult guardianship, especially the guardianship of the elderly.

\footnotetext{
${ }^{6}$ Article 29 of the GPCL provides that parents of juvenile have the right to appoint guardians for their children by wills.

${ }^{7}$ Article 31(3) of GPCL provides that whether it is in minor guardianship or adults guardianship, a temporary guardian shall be appointed by the residents' committees, the village committee, the civil affairs department or other organizations prescribed by law in the place where the persons under guardianship is located. Article 36 (1) stipulates that when the guardian's qualification is revoked, if necessary, according to the application of the individual or organization the temporary guardianship measures shall be arranged by the court.

${ }^{8}$ Under the Article 33, an adult with full civil capacity may determine his guardian in written form in consultation with his direct relatives or other individuals or organizations who wish to act as guardians. When the adult loses or partially loses his capacity for civil conduct, the guardian under consultation shall execution of his guardianship duty.

${ }^{9}$ Article 36 list reasons to revoke the guardianship of the guardian, such as to seriously impair the physical and mental health of the persons under guardianship; being negligent in performing the guardianship duty, or unable to perform the guardianship duty and refusing to entrust the guardianship duty in part or in whole to others, causing the person under guardianship to be in a state of distress; performing other acts that seriously infringe upon the lawful rights and interests of the person under guardianship. Article 39 list reasons to terminate the guardianship relationship, such as the ward obtains or regains full capacity for civil conduct; the guardian becomes incapable of guardianship; the ward or the guardian die; the guardian relationship otherwise terminates as determined by a people's court.

${ }^{10}$ Yu Fei.(2012). On "Favor Principle" in Private International Law - Together with Discussion over the Rules of the "Law of Applicable of Law for Foreign-related Civil Relations of the People's Republic of China". In Huang Jin, Xiao yongping \& Liu Renshan (Eds.), Chinese Yearbook of Private International Law and Comparative Law (p.67). Peking: Peking University Press. See also Guo Yujun (2011). Introspection and Consummatation of Legislation on Private International Law in China-the Perspective of the Law of the PRC on Application of Laws to Foreign-Related Civil Relations. Tsinghua Law Journal, 5, 161 .
} 
Second, the meaning of "one party" is controversial. Under Article 30, the governing law should be chosen from the law of one party's habitual residence or nationality, depending on which is in favor of protecting the rights and interests of the ward. However, it is not sure whether the "one party" refers to all parties to the dispute, or only refers to the guardian and the ward.

Third, there is no standard of deciding the "law is more favorable to the protection of the rights of the ward". It requires the judge to determine on the basis of the case's specific circumstances, but the judge enjoys much discretion to evaluate which right should be protected.

Fourth, the intended guardianship needs consideration of the autonomy of parties in the level of conflict of laws. Considering the adult guardianship, especially the guardianship of the elderly was adopted by the GPCL, if the elderly signs a guardianship contract with a willing people, which contains a choice of law clause, the Conflicts law has reasonable reason to allow the parties to choose the applicable law for guardianship.

\section{A Survey of Judicial Practice on Foreign-related Guardianship in Chinese Courts}

In order to explore the judicial practice of Chinese courts on foreign-related guardianship after the implementation of the Conflicts Act, I found 16 judgments ${ }^{11}$ from April 1, 2011 ${ }^{12}$ to November 15, 2018 by retrieving the China Judgments Online (www.wenshu.court.gov.cn) and other official websites of the Provincial Courts provinces and city courts. To sum up the above 16 cases, the following characteristics can be found.

First, the foreign elements are mostly attribute to foreign-related subject, including 6 cases $^{13}$ involving residents from Hong Kong, Macao and Taiwan.

Second, minor guardianship are more than adult guardianship among those cases. There are 14 foreign-related cases involving minor guardianship, while the cause of action, there into 4 of them, is divorce disputes. Only $2^{14}$ of 16 judgments involving the adult guardianship, while the cause of action is the declaration of a citizen's incapacity.

Third, the courts usually form a panel according to the ordinary procedure to hear the case involving foreign-related guardianship. Only in 1 case, ${ }^{15}$ a summary procedure was used, and in 5 cases $^{16}$ the special procedures were opened.

Finally, as the choice of governing law issue, only 1 judgment ${ }^{17}$ did not explain the choice-of-law process and basis, other 15 judgments explained the basis of choice of law. But all judgments applied Chinese law as the governing law.

After a detailed analysis of these judgments, it can be found that there are some deficiencies in choosing law applicable to the foreign-related guardianship by Chinese courts.

${ }^{11}$ According to Article 4 of the Provisions of the Supreme People's Court (SPC) on the Publication of Judgments by the People's Court on the Internet (adopted by the Judicial Committee of the Supreme People's Court at its 1689th meeting on July 25, 2016 and implemented on October 1, 2016), the judgments issued by the people's court shall not be published on the Internet if it concerns divorce proceedings or the guardianship and maintenance of minor. After this SPC's judicial interpretation, seldom courts would publish the judgments of Foreign-related guardianship on the Internet. The 16 collected cases listed as follows: Pi v. Wang, [2016] Jing 01 Min Xia Zhong No 288; Cao Fengzhen v. Zhong Ming, [2016] Yu 0491 Min Te No 1; Zhang v. Zhang \& Yu, [2016] Yu 01 Min Xia Zhong No 2517; Zhang Zhijie v. Yu Xioling \& Zhang Zhihui, [2016] Yu 01 Min Xia Zhong No 2523; Gao v. Li, [2015] Yanzhong Min San Chu Zi No 734; Tang v. Zhang, [2015] Qinbei Min Chu Zi No 932; Hu v. Yu, [2015] Min Min Yi Te Zi No 39; Zheng Yuzheng v. Guo Yunling \& Huang Jinyu, [2015] Zhu Heng Fa Min Te Zi No 1; Tang v.Yan, [2015] Lu Min Yi Chu Zi No 215; Sun v. Sun, [2014] Shen Fu Fa Min Yi Chu Zi No 579; Wang Jingchun v. Cai Meijin, [2014] Xia Min Zhong Zi No 2971; Wang v. Cai, [2014] Hai Min Chu Zi No 1707; Wang Xiang v. Yu Lingli,[2014] Hang Xi Min Te Zi No 17; Wei v. Lu, [2014] Hui Yun Fa Min Chu Zi No 563; Chen Xianhui v. Shou Guiying, [2014] Hang Xi Min Te Zi No 24; Chen v. Guo, [2013] Hang Xi Min Chu Zi No 1647.

${ }^{12}$ The Conflict Law came into force on April 1, 2011.

${ }^{13}$ Cao Fengzhen v. Zhong Ming, [2016] Yu 0491 Min Te No 1; Zheng Yuzheng v. Guo Yunling \& Huang Jinyu, [2015] Zhu Heng Fa Min Te Zi No 1; Tang v. Zhang, [2015] Qinbei Min Chu Zi No 932; Wang v. Cai, [2014] Hai Min Chu Zi No 1707; Wang Jingchun v. Cai Meijin, [2014] Xia Min Zhong Zi No 2971; Sun v. Sun, [2014] Shen Fu Fa Min Yi Chu Zi No 579.

${ }^{14}$ Wang Xiang v. Yu Lingli, [2014] Hang Xi Min Te Zi No 17; Chen Xianhui v. Shou Guiying, [2014] Hang Xi Min Te Zi No 24.

${ }^{15}$ Wang v. Cai, [2014] Hai Min Chu Zi No 1707.

${ }^{16}$ Cao Fengzhen v. Zhong Ming, [2016] Yu 0491 Min Te No 1; Zheng Yuzheng v. Guo Yunling \& Huang Jinyu, [2015] Zhu Heng Fa Min Te Zi No 1; Hu v. Yu, [2015] Min Min Yi Te Zi No39; Wang Xiang v. Yu Lingli, [2014] Hang Xi Min Te Zi No 17; Chen Xianhui v. Shou Guiying, [2014] Hang Xi Min Te Zi No 24.

${ }^{17}$ Tang v. Zhang, [2015] Qinbei Min Chu Zi No 932. 
First, Chinese courts usually apply the governing law of divorce to resolve the guardianship issue without distinction guardianship from divorce. In dealing with divorce disputes, if the parties present guardianship and maintenance issues, Chinese courts generally deal with divorce matters as well as the rights of guardianship and maintenance matters, and regard the issue of foreign-related guardianship as subsidiary issue of foreign-related divorce, so the governing law of foreign-related divorce may be applied to resolve the guardianship and maintenance issues. ${ }^{18}$

Second, Chinese courts sometimes did not distinguish guardianship from parent-child relationship in the minor guardianship cases. ${ }^{19}$ Because the generalized concept of "guardianship" by Chinese substantive law did not distinguish parent-child relationship and guardianship, while Articles 25 and 30 of the Conflicts Act provide respectively two conflict rules for parent-child relationship and guardianship, Chinese courts are sometimes unaware of which rule to apply.

Third, Chinese courts usually do not illustrate how to identify "which law is more favorable to the protection of the rights of the ward", just directly apply Chinese law when both parties located in China. Only 1 of 16 judgments detailing the considering factors of " in favor of the ward". ${ }^{20}$

\section{Our Suggestions for Perfection}

Our suggestions for perfection are also divided into two levels: substantive law and conflict of laws. In the level of substantive law, we suggest

1. To clarify the considering factors of " in favor of the ward" based on the different types of guardianship. For minor guardianship, these consideration factors may include: father, mother or both parents' advice; the wishes of the minors; the relationship between minors and one or both parents, siblings and other of the best interests of affected people; fitness of family and school environment; gender, age and family; mental and physical health conditions associated with the above people; the discretion of the judge. ${ }^{21}$

\footnotetext{
${ }^{18}$ Chen v. Guo, [2013] Hang Xi Min Chu Zi No 1647. In this case, the court determined the case as a civil action involving foreign elements and held that it had jurisdiction over the case. And then the court applies Chinese law as the governing law in accordance with Article 27 of the Conflicts Law, which stipulates that "the laws at the locality of the court shall apply to a divorce by litigation." However, the uniform application of article 27 of the Conflicts Law in the judgment directly determines that the applicable law for child custody is also Chinese law, rather than separately analyzing the application of the law for child guardianship. See also Tang v.Yan, [2015] Lu Min Yi Chu Zi No 215, in this case, the people's Court of Lushui county also made a judgment on the guardianship issue according to the applicable law of divorce, that is, the court did not apply the applicable law of guardianship relationship for this issue. After being summoned by the court, the defendant Yan failed to appear in court, which shall be deemed as renounced the right of direct guardianship of the children. Meanwhile, the plaintiff requested that Tang was the guardian of the children.

${ }^{19}$ Wang Jingchun v. Cai Meijin, [2014] Xia Min Zhong Zi No 2971, the judgment holds that "The relationship between parents and their children is not affected by the divorce of parents. The children are still owned by both parties, no matter which party directly raises after the divorce. Guardianship is the guardian's right of identity, which is a supervision and protection to the children's personal rights and property rights. The exercise of guardianship should be conducive to the physical and mental health of children and should not increase their psychological burden or obviously violate their personal wishes." The judgment made by the court did not distinguish parent-child relationship, maintenance and guardianship.

${ }^{20}$ Wang v. Cai, [2014] Hai Min Chu Zi No 1707, the judgment stated that "Guardianship is an identity right based on the relationship between parents and children. The exercise of guardianship should conform to the principle of the best interests of children. The best interests in the present case indicates that exercising guardianship shall never injure Wang's physical and mental health, increase his psychological burden,or violate his personal wishes obviously. Wang can make a statement equal to his age and intellegence at the age of seventeen, even if he's underage. During the court hearing, Wang clearly expressed that he won't tell the plaintiff about his school address and residence, preventing the plaintiff's influence on his study. The court held that Wang's personal wishes should be respected."

${ }^{21}$ The most direct embodiment of the principle of being in favor of the interests of wards is to realize the "best interests of minors", which means truly fulfill the interests of the minor rather than the guardian, and authentically conform the psychological maturity of the minors so that they can gradually participate in the decision. The formulation of "the best interests of minors" needs to focus on measuring their health, happiness and dignity, pay attention to their right to survival and development, encourage them to participate in autonomous affairs, prevent excessive intervention by their guardians, which means granting priority special protection. See Cao Xianyu, Research on the Parentage Law under the Principle of the Best Interest of Child, 64 (Qunzhong Publishing 2015).
} 
For guardianship of adults, these factors are: non-discrimination and equal consideration; considering all the relevant circumstances; considering the possibility of recovery; permitting and encouraging the ward to participate in decisions; consideration of the person's past and present wishes and feelings, beliefs and values; seeking advice from relatives, caregivers, or others to determine the guardian's willing. ${ }^{22}$

2. To specify the content of the personal guardianship and the property guardianship by the legislative model of summarization plus enumeration. Except the personal guardian's obligation on live care and physical health, the physical custody of minors should be supplemented with the determination of the residence, education and parenting style, etc. In the personal guardianship of adults, the guardian should consider the needs of different levels, both their physical and mental state and living conditions, respect their independent living rights, to acheive the guardianship and assistance parallelly. The property guardianship should make clear the property management rules, property catalogue, using specification and so on.

3 . To clear-cut the difference among guardianship, maintenance and support parent. ${ }^{23}$

4. To perfect the legislations on the content of guardianship of children after divorce and guardianship of elderly, and to consider the possibility of applying guardianship to some specific physical disability adults.

In the level of conflicts law, we suggest

1. To clarify the scope of guardianship following the substantive law. The guardianship under article 30 shall be clarified as the establishment, change and termination of the guardianship, the qualification and scope of the guardianship, the responsibility of guardianship, as well as a series of problems arising from the guardianship management process. It is also clear that article 30 includes both the minors guardianship and the adults guardianship, as well as the custody of persons and the custody of property. Finally, guardianship not only includes legal guardianship, but also includes new intentional guardianship and testamentary guardianship.

2. To make clear the meaning of "parties" in Article 30 of the Conflicts Act. Generally the "parties" refer to the guardian and ward when the guardianship establish, alter, terminate involving the status of the ward, but the "parties" shall be extensively interpreted as people involved in the dispute, when it relates to the specific content of guardianship. 3. To estimate which law in favor of the ward according to lex fori. ${ }^{24}$ The criterion may refer to the relevant provisions of the substantive law.

4. To allow the parties to choose the applicable law in some specific kinds of guardianship.

5. To apply the conflict rule for guardianship Preferentially when the conflict rules for the parent-child conflict and guardianship are coincidental.

\footnotetext{
${ }^{22}$ In adult guardianship, it is the principle of being in favor of the interests of wards to consider the following aspects: the ward's autonomy, the least restriction of his behavior and the protection of his best interests. The principle of best interests has frequently appeared in recent national legislation on adult guardianship. In the process of dealing with the property management and personal guardianship, the guardian must give priority to their wish and well-being. See Li Xia, Research on Adult Guardianship: the Perspective of Human Rights, 85 (China University of Political Science and Law 2012).

${ }^{23}$ The practice of unifying or confusing legislation without distinguishing the contents of the two systems will not only leading problems to the domestic judicial practice, but also to the hearing of foreign-related family disputes. For the domestic judicial practice, if the cases of guardianship disputes and maintenance disputes are not distinguished, the cause of action can be determined optionally. For foreign-related disputes, if the substantive law is Chinese law, the relevant legislation should be the guardianship legislation but actually applied the maintenance legislation, which can hardly be recognized.

${ }^{24}$ Firstly, as this article is a provision of conflict rules, the applicable law of the legal relationship of foreign-related guardianship has not been determined before judging whether it is "conducive to protecting the rights and interests of the guardian". Therefore, it is logically impossible to apply the applicable law of the legal relationship of foreign-related guardianship. Secondly, some countries conjunctively stipulated foreign (interstate) guardianship of jurisdiction and applicable law, namely when determining jurisdiction over a case is taken to the principle of protecting the person under guardianship. Courts of jurisdiction usually have a substantial connection to the case. If the parties have objection to the jurisdiction of the case, they can raise objection to the jurisdiction. If they do not raise objection to the jurisdiction, it shows to some extent that they approve that the court has jurisdiction over the case. The court with jurisdiction applies its conflict rules to select the proper law, and it is reasonable to judge the content of conflict rules according to the lex fori. Thirdly, the judges are more familiar with the relevant provisions of domestic guardianship laws, and their judgment will be made more efficient. In addition, for some of the guardianship items, many countries' the substantive law also provides for the principle of protecting the person under guardianship. The judgment in favor of protecting the guardian in the choice of law proceding is based on the lex fori. After determining the applicable law of the case, the specific substantive law is applied to judge the case for the specific guardianship dispute in the case, which can also achieve the purpose of protecting the rights and interests of the ward.
} 


\section{Reference}

\section{Books:}

Atkin, B. \& Banda, F. (2015), The international survey of family law, Bristol: Jordon Publishing.

Blair, D. M. et al.(2015), Family law in world community: cases, materials, and problems in comparative an international family law (3rd ed.), Durham: Carolina Academic Press .

Dayton, A. K.(2014), Comparative perspectives on adult guardianship, Durham: Carolina Academic Press .

Du, H. F. (2014), International civil abduction of children: interpretation, implementation and application of the Hague Convention, Beijing: Law Press · China.

Estin, A. L. (2016), International family law desk book (2nd ed.), Chicago: American Bar Association .

Hodson, D. (2015), The international family law practice (4th ed.), Bristol: Jordon Publishing .

$\mathrm{Li}, \mathrm{X}$. (2012), A study of adult guardianship system from the perspective of human rights, Beijing: China University of Political Science and Law Press.

Scherp, J. M. (2016), The present and future of European family law: volume iv of European family law, Cheltham: Edward Eglar.

Walker, L. (2015), Maintenance and child support in private international law, Oxford and Portland: Hart Publishing.

Wang, J. L. (2014), A study on private international law conventions for the protection of children's rights and their implementation mechanisms: A case study of the Hague Convention, Beijing: Law Press - China.

\section{Journals:}

Guo Y. J. (2011), Choice of law for marriage and family in law of the application of law for foreign-related civil relations, Tribune of Political Science and Law, (3):21-27.

Li, X. (2015), The trends of the adult guardianship, China Legal Science, (2):199-219.

Wang, J. L. (2010), Legislation applicable to foreign marriage relationships in China, Modern Law Science, (4):159172.

Yuan, F. Q. (2014), Reflections and reconstruction of the protection system for the weak in China's private international law, Studies in Law and Business, (6):98-106. 